\title{
Advantageous Impact of Spices in Controlling Urinary Tract Infections
}

\author{
Rabia Bashir, Naureen Naeem, Aisha Waheed Qurashi, and Nayyab Sultan
}

\section{ABSTRACT}

Urinary tract infection (UTI) can be a standard sickness allopathic treatment with numerous antibiotics might additionally purpose facet effects. The microorganism causing contamination can broaden resistance to, the prevailing antibiotics that are prescribed if the drugs are hired for an extended time. Those issues have caused countless exploration of varied modes of remedy and exchange treatment plans. Herbs have a symbolic record and proven to be very powerful in stopping and treating tract infections.

Keywords: Antibacterial activity, Escherichia coli, Multi-drug resistant, Minimum Inhibitory concentration.

\section{INTRODUCTION}

A tract infection (UTI) is contamination at some point of which the presence and multiplication of microorganisms occur inside any a part of the urogenital device, e.g., Kidneys, ureters, bladder, and urethra. The irritation of urinary transition epithelium way to the presence of microorganism within the tract additionally described the tract infections. UTI also is known as bladder infections. Those contaminations that can include decrease tractor now and then both the decrease and pinnacle urinary tracts. Cystitis is that the scenario which describes lower UTIs consists of dysuria (hassle in urination), suprapubic tenderness (decrease stomachache), urinary frequency and urgency [1].

The microorganisms that are blanketed in inflicting tract illnesses are essentially Gram poor microbes. Maximum vital is Escherichia coli (E. Coli) which is display in most cases. Antimicrobials are predominant subject and include within the tract ailment remedy. The risk additives which can be commonplace in UTI comprise sexual motion, the use of antimicrobial resistance, month-to-month cycle duration, hereditary capabilities, and bacterial harmfulness [2].

The prevalence of UTIs varies with age and sex. Companies which can be at elevated chance for infections consist of neonates, younger girls, and older guys, humans with structural abnormalities of the tract or
Submitted : February 25, 2021

Published : July 03, 2021

ISSN: 2593-8339

DOI: $10.24018 /$ ejmed.2021.3.4.738

\section{Rabia Bashir*}

M-phil research student, Lahore Garrison University, Pakistan.

(e-mail: rabibashir32@gmail.com Dr Naureen Naeem (Supervisor) Coordinator Post Graduate Studies, Lahore Garrison University, Pakistan.

(e-mail: naureen.naeem ${ }^{@} 1$ gu.edu.pk) Dr. AishaWaheedQurashi

HEC Approved PhD Supervisor, Chairperson Department of Biology, Lahore Garrison University, Pakistan.

(e-mail: aishawaheedqureshi@1gu.edu.pk) Nayyab Sultan

M-phil student, Goverment College of University of Lahore, Pakistan.

*Corresponding Author immunosuppressant. UTI maximum usually arises within the girls than in the men. Up to $40 \%$ of women will revel in symptomatic UTI at a brief time for the duration of their life. Pregnant girls have 4-10\% incidence of bacteriuria which has been confirmed to boom the danger of pre-mature start. The hospital obtained UTIs may moreover money owed for 50 you cope with infections and are a large cause of Gram poor Bacilli, which reasons excessive mortality [3].

Organisms inflicting UTI are often from the aerobic members of the fecal plant life. Most of the humans of uncomplicated UTI (95\%) are attributable to one organism. In assessment, infections amongst hospitalized patients, patients with urinary catheters, or people with structural abnormalities of the urinary may also need to be monomicrobial. Gram inferior rods are most everyday pathogens involved in these infections. Escherichia coli motive eighty\% of acute conditions in patients without tract abnormalities [4].

Plant, animal, and microbes constitute a massive supply of compounds with medicinal residences. Given that historical time, human beings are using spices as nutritional agents [5].

In keeping with the U.S. Food and Drug Administration (FDA), the spice is an "aromatic vegetable substance inside the complete, damaged, or floor form, the many function of which in food is seasoning rather than nutrients" and from which "no portion of any critical oil or one of a kind flavoring principle has been removed" [6]. 
More than 100 varieties of spices are produced sooner or later of the planet. Asia is that the principal chief for the assembly of herbs, especially of cinnamon, pepper, nutmeg, cloves, and ginger, whilst Europe grows basil, bay leaves, celery leaves, chives, coriander, dill guidelines, thyme, and watercress particularly. In us, alternatively, pepper, nutmeg, ginger, allspice, and benni seed are specifically produced [7].

Even although spices are utilized in unique purpose for rituals, cosmetics, and perfumery, their flavouring, colouring and, mostly, preservative houses have based massive programs both inside the traditional food preparations and in the food industry. In many compounds isolated from spices have proven antimicrobial hobby in opposition to some of the most commonplace microorganisms that have an impact at the food exceptional and term [8].

The advent of spices via the meals has numerous useful outcomes additionally they will stimulate the secretion of saliva, promote the digestion, prevent from bloodless and influenza, and reduce nausea and vomiting [9], [10].

Spices are crucial to humanity for the purpose that begins of history. Because of their sturdy preservative pleasant, herbs were considerably applied for the synthetic purpose. Many spices are wont to exchange the bodily appearance of meals. For example, pepper and turmeric modified the colouration, look and therefore, the flavour of food with many fitness benefits. Ginger, Cranberry, cumin, and cinnamon enhance digestion, taken into consideration top for spleen and sore throats. The beneficial impact of spices is not clinically verified. But conventional practices emphasize the fitness blessings of spices. Other organic functions of spices are highlighted in the latest studies, together with antimicrobial, antioxidant, and anti-inflammatory [8].

Spices are used as food and flavouring and as remedy and meals preservatives in latest decades. Many spices together with clove, oregano, thyme, cinnamon, and cumin were applied to treat infectious diseases or defend food because of the reality they had been experimentally proved to very own antimicrobial sports in competition to pathogenic and spoilage fungi and microorganism [11].

Antimicrobial sellers are the secondary metabolites of the spices which can be a majority of that are typically identified as certain substances for meals with insignificant adverse outcomes. Spices are probably applicants to get and increase new antimicrobial dealers closer to foodborne and human pathogens. This overview summarizes the scientific studies on the antibacterial and antifungal sports of spices. [12].

\section{ANTIMICROBIAL INTEREST IN VITRO}

Many articles posted within the previous few months have defined the antimicrobial activities of spices in vitro. Extracts of complete flora or part of them, received with numerous solvents (which consist of ethanol, methanol, ester, and water) are tested towards microbes [8].

Their vital oils or lively compounds, on my own or together, had been moreover wont to check the interest towards specific microbes. Special techniques are wont to make use of the screening those are Disc-diffusion, dropagar-diffusion, micro broth dilution, and direct-contact method in agar [13], [14].
In step with these reports, spices own an, in reality, a massive spectrum of activity closer to Gram-effective and Gram-horrific bacteria, yeasts and moulds. The bush-basil crucial oils have an antimicrobial hobby in opposition to Listeria innocua, Serratia marcenscens, Pseudomonas fragi, P. Fluorescence, Aeromonas hydrophila, Shewanella putrefaciens, Achromobacter denitrificans, Enterobacter amnigenus, En. Gergoviae, and Alcaligenes faecalis, and towards the yeasts Yarrowia lipolytic, baker's yeast, Candida zeylanoides, Debaryomyces hansenii, and Pichia Carson [15].

The antimicrobial pastime of spices may vary regularly with the kinds of spice (foundation and bioactive compounds); distinct microorganism can react in several approaches [16]. Oregano risky oil showed better antimicrobial hobby toward Listeria monocytogenes compared to Escherichia coli. Huacatay and basil essential oils had been active closer to Staphylococcus aureus and Bacillus subtilis [17].

Radwan et al. [18] referred to that amongst 22 standard spice extracts, turmeric, and nutmeg extracts were the most energetic in opposition to unique plant pathogens belonging to the genus Colletotrichum. In every other examine, wherein 23 spice extracts were studied, Olax subscorpioidea extract confirmed the very high antifungal interest, particularly in opposition to C. Albicans and C. Tropicalis [19].

Ferreira et al. [20] moreover pronounced a lower (ninetynine. nine and $99.6 \%$ ) of aflatoxin B1 and B2 while zero. Five\% of turmeric turned into even as equal turmeric completely inhibited the biomass of Fusarium graminearum and its zearalenone production, at three. Five and three $\mathrm{mg} / \mathrm{mL}$, respectively [21].

Finally, the antiviral hobby of Mexican oregano in the direction of some viruses (i.e., acyclovir-resistant herpes simplex virus kind 1 (ACVR-HHV-1), human respiration syncytial virus (HRSV), and human rotavirus) has been pronounced (Pilau et al., 2011). Spices substances may impact numerous targets, like microorganism's mobile wall, enzymes, or their genetic fabric via the modulation of specific genes [16].

\section{ENHANCEMENT OF THE ANTIMICROBIAL ACTIVITY IN VITRO}

To enhance the antimicrobial capability of spices or their constituents, the use of combined extracts or herbal compounds having certainly one-of-a-kind origins are suggested [22].

In a maximum of the cases, spices confirmed synergistic activities /results. As an example, the antimicrobial interest of basil, oregano, bergamot, and perilla crucial oils by myself or in combinations, had been tested. In some other study, confirmed the additive effect of citric and linalool in the direction of $S$. Cerevisiae. Linalool reduced markedly the amount of citric wanted for an equal effect.

The use of spice oils along thing other preservation techniques has been moreover assessed. For instance, low environment healthier the susceptibility of E. Coli and $S$. Enteritidis to oregano, lemongrass, or cinnamon critical oils in vitro [23]. 


\section{Mode of Antimicrobial Action of Spices}

Although the antimicrobial consequences of spices and their derivates are examined toward a fantastic range of microorganisms over the years, their mode of movement remains no longer understood.

Spices and their critical oils can comprise many various bioactive compounds present in variable amounts. The bioactive factors of spices are frequently divided into the volatile and non-risky compound. The number one is mainly liable for the antimicrobial activity of spices. They will be divided into four groups: terpenes, terpenoids, phenylpropenes, and "others" (such as products of degradation; Terpenes are evaluated as lesser lively antimicrobial compounds amongst the opposite compounds. As an example, the weak hobby of $\rho$-cymene, one in each of the most components of thyme, is specifically related to its motion as a substitution membrane impurity. It can affect the melting temperature and therefore, the membrane capability, which successively reasons a decrease in cell motility [16].

The clove; oregano, lavender, and rosemary essential oils very own quorum sensing inhibitory activity. As an example, molecules like furan ones are often internalized with the aid of microorganism, bind to Lux R-kind proteins, and destabilize them. During this way, spices could affect the motility, swarming, and bio movie production of bacteria [24].

Overall, the antimicrobial hobby of spices can't be confirmed based pleasant on the movement of 1 compound. The final interest may be a synergistic effect of extra additives [25].

\section{A. Cumin}

Cumin (Cuminum cyminum) is an aromatic plant belonging to the Apiaceous family. Cumin has been used since historical time as a component in foods in the Middle East, and cumin seeds have lengthy been used as antiseptic and disinfectant in India [26]. The bioactive compounds of cumin are Cuminaldehyde, cymene, and terpenoids [27].

\section{B. Antimicrobial Activities of Cumin}

In a study, the antimicrobial activities of cumin seeds towards E. Coli, S. Aureus, S. Faecalis, P. Aeruginosa, and $K$. Pneumonia have been investigated through agar diffusion and dilution techniques. E. Coli, S. Aureus, and S. Faecalis were susceptive to various cumin dilutions even as $P$. Aeruginosa and K. Pneumonia were resistant...The cumin became fungicidal to most of the fungal species and exerted an incredible spectrum of fungal toxicity at MIC $(0.6 \mu \mathrm{L} / \mathrm{mL})$ closer to all 19 meals borne fungi strains except $R$. Stolonifer [28].

Antimicrobial sports in the direction of E. Coli, S. Aureus, P. Aeruginosa, A. Niger, A. parasiticus, and C. Albicans $u$ sing the disk diffusion method. Both microwave and conventionally (oven) roasted cumin oils had similar antimicrobial consequences on microorganisms tested and have been less complicated than the ones of uncooked oils. [29].

The outcomes of ã-irradiation on the antibacterial activities of cumin in opposition to E. Coli, P. Aeruginosa, B. Cereus, and S. Aureus, via the agar nicely diffusion method and disk diffusion technique. The outcomes indicated that cumin exerted antibacterial results on bacteria tested, and ãirradiation to cumin seeds had no splendid consequences on the antimicrobial sports activities of cumin [30].

\section{Garlic}

Garlic (Allium sativum) belongs to the Liliaceous family. The antimicrobial sports of garlic are recognized for several years, and consequently, the active component emerges as identified as allicin, each day thiosulfinate (2-propenyl-2propanediol sulfonate) [31].

\section{Antimicrobial Activities of Garlic}

In some other observe, it had been examined that the antimicrobial consequences of fresh garlic, garlic powder, and garlic oil on microorganisms in raw bird sausage with the useful resource of aerobic plate count located to be full size.

Garlic substances showed antimicrobial activities in such an order: smooth garlic > garlic powder > garlic oil > butylated hydroxyanisole. Another takes a look at moreover assessed the antimicrobial sports of dried garlic powders made via one-of-a-kind drying techniques against S. Aureus, E. Coli, S. Typhimurium, B. Cereus and a combined lactic tradition containing Lactobacillus delbrueckii subsp. Bulgaricus and Streptococcus thermopiles'. Fresh garlic exhibited the very splendid sports activities followed with the resource of freeze-dried powder. The keeping of energetic components answerable for antimicrobial sports activities come to be specially laid low with every drying temperature and time [32].

Chopped garlic at concentrations from $0 \%$ to $10 \%$ had been investigated for the antimicrobial consequences in hamburger (saved at the fridge and ambient temperatures) and uncooked meatballs (stored at room temperature) through figuring out the colony counts of total cardio mesophilic bacteria, yeast, and moulds at 2, 6, 12, and $24 \mathrm{~h}$ after storage. The outcomes indicated that chopped garlic delayed the enlargement of microorganisms in-floor meat, which relied on the garlic concentrations. The addition of garlic $(5 \%$ or $10 \%)$ to the raw meatball blend reduced the microorganism counting, in terms of total aerobic mesophilic bacteria, yeast, and mould counts [33].

\section{E. Cranberry}

Cranberry (Vaccinium macrocarpon), a Native American fruit, has traditionally been wonted to treat tract infections, diarrhea, and septicemia. Cranberries comprise many bioactive compounds like proanthocyanidins and flavones which have antioxidant, ant mutagenic, anti hypercholesterolemic and other fitness blessings. Cranberry tannins have laboratory proof for anti-clotting residences and should prevent ordinary tract infections in women; but a evaluate of available research concluded that there might be little proof to guide the efficacy of cranberry products in treating UTIs [34].

\section{F. The Antimicrobial Interest of Cranberry}

Berry fruits are rich resources of bioactive compounds, like phenolic and natural acids, which can maintain antimicrobial sports. Antimicrobial residences of pure phenolic compounds and phenolic extracts from Finnish berries in competition to probiotic microorganism and one of a kind intestinal bacterium; the authors discovered carboxylic acid bacteria 
(LAB) had been extra resistant than the alternative microorganism (popular E. Coli, Salmonella spp.) to phenol compounds [35].

Vaccinium macrocarpon, American Cranberry, has tremendous commercial value and offers crucial health advantages like preventing tract infections. Photochemical in the cranberries are now identified to possess the ability for inhibition of development of maximum cancers and cardiovascular diseases [34], [36].

Although Cranberry's unique mechanism of action in UTI prophylaxis is unknown, one attainable speculation is that of its compound's fructose and an unrecognized polymeric compound - inhibit the adherence of microorganism, especially E. Coli, to epithelial cells within the bladder wall to prevent colonization [37]. Cranberries have long been the primary intention of interest for his or her beneficial consequences in preventing tract infections. Cranberries contain two compounds with anti-adherence residences that save you fabricated Escherichia coli from adhering to uroepithelial cells inside the tract [34], [38].

\section{CONCLUSION}

Starting from the preparation of the meal, spices will have an impact on each food spoilage microorganisms (meals preservation) and human pathogens (meals safety) way to the antimicrobial and antifungal activity of their herbal ingredients. Spices are provided from herbal herbs and plants and usually diagnosed as safe (GRAS) utilizing the manner of the American Food and Drug Administration (FDA). However, the need for a high number of herbal compounds constitutes the most hassle for effective performance in opposition to microorganisms.

Mostly, their organoleptic traits may impact the consequences of in vitro and in vivo trials. For this cause, mixtures of spices their herbal compounds, applied without or with other era represent a promising alternative to avoid this problem. Synergistic effects can cause are duction of both natural compounds used and remedy applied. In several instances, additive sports also are stated. The check of spices, herbal combinations, and novel aggregate technology is often a supply of concept for developing novel or superior molecules acting towards spoilage microorganisms.

\section{REFERENCES}

[1] Heidler S. et al., 2007. The explanation of lower tract symptoms in females: analysis of a health screening project. Eur. Urol. 52, 17441750 .

[2] Hisano M, Bruschini H, Nico demo AC, Srougi M, 2011.Cranberries and lower tract infection prevention.

[3] Kumar. M, Maneemegalai S. (2008). Evaluation of Larvicidal Effect of Lantana Camara Linn against Mosquito Species Aedes aegypti and Culex quinquefasciatus. Advances in Biological Research Vol.2 (3-4): 39-43.

[4] Reddy. M, Rao. M, Reddy. A, Reddy. M and Chary S. (2004). University Botany- Iii :(Plant Taxonomy, Plant Embryology, Plant Physiology) 3ed., New Age International,149- 152.

[5] Kaefer, CM, and Milner JA 2008.The role of herbs and spices in cancer prevention. J. Nutr. Biochem. 19, 347-361. doi:10.1016/j.jnutbio.2007.11.003.

[6] Prasad S, Gupta SC., and Aggarwal B B.2011.Micronutrients and cancer: add spice to your life. Nutr.Diet Cancer 2348.doi:10.1007/978-94-007-2923-0_2.
[7] Alves-Silva J M,Diasdos Santos S M ,Pintado M E, Pérez-Álvarez J A Fernández-López J, and Viuda-Martos M,2013.Chemical composition and in vitro antimicrobial, antifungal and antioxidant properties of essential oils obtained from some herbs widely utilized in Portugal. Food Control 32,371-378. doi: 10.1016/j.foodcont.2012.12.022.

[8] Camilli A, and Bassler BL. 2006. Bacterial small-molecule signaling pathways. Science 311, 1113-1116.doi:10.1126/science.1121357.

[9] Kedia, A, Prakash B, Mishra KP, and Dubey NK, 2014. Antifungal and anti aflatoxigenic properties of Cuminumcyminum (L.) Seed volatile oil and its efficacy as a preservative in stored commodities. Int. J. Food Microbiol. 168-169, 1-7. doi:10.1016/j.ijfoodmicro.2013.10.008.

[10] Puupponen-Pimia"R, Nohynek L, Meier C, Kahkonen M, Heinonen M, \& Hopia A, et al., 2001. Antimicrobial properties of phenolic compounds from berries. Journal of Applied Microbiology,90,494e507.

[11] LiuY, Black MA, Caron L, Camesano T, 2006. Role of fruit juice on molecular-surface characteristics and adhesion behavior of Escherichia coli. Biotechnology and Bio-engineering, 93(2), 297-305.

[12] Harkins KJ, 2000. What's the utilization of cranberry juice? Age and Ageing, 29: 9-12.

[13] Asghari G, Nourallahi H, Havaie SA, Issa L, 2006. Antimicrobial activity of Otostegia persica bios extracts. Res. Pharm. Sci. 1: 52-58.

[14] Anis Ahmad Chaudhry et al., 2018.Urinary Tract Infections Caused by ESBL Producing E. coli in Diabetes Mellitus: Alternative Approaches for Treatment and Management. Review ArticleVol.11, Issue: 2.

[15] Ali et al., 2016. The pharmacological activities of cumin - A review. (e)-ISSN: 2250-3013, (p) ISSN: 2319-4219 Volume 6, Issue 6 Version.

[16] Anonymous, 2011. Improvement and Management Subcommittee on tract Infection committee on Quality. Management of the initial UTI in febrile infants and youngsters 2 to 24 months 128:595e610.

[17] Abriouel H, Benomar N, Gálvez A, and Pulido PR,2014. Preservation of Manzanillaalore a cracked green table olives by highly prostatic pressure treatments singly or together with natural antimicrobials. LWT Food Sci. Technol. 56, 427-431. doi:10.1016/j.lwt.2013.09.012.

[18] Agrahari P, and Singh D K. 2014.A review on the pharmacological aspects of Carumcarvi. J. Biol. Earths. 4, M1-M13.

[19] Krebs H C, 2003.Antibacterial and antifungal activities of Quassia undulate and quassia extracts in vitro. Afr. J.Med.Sci. 32, 353-356.

[20] Al-Dhubiab B sE, 2012.Pharmaceutical applications and phytochemicals profile of Cinnamomum burmannii. Pharmacogn. Rev. 6,125-131.doi:10.4103/0973-7847.99946.

[21] Ali M A, Rabii NS, Garbaj M A, and Abolghait SK,2014. Antibacterial effect of olive (Oleaeuropaea L.) Leaves extract in raw peeled undefined shrimp (Penaeussemisulcatus). Int. J. Vet. Sci. Med. 2, 5356.doi: 10.1016/j.ijvsm.2014.04.002.

[22] Al-QudahM A,Al-Jaber H I,Muhaidat R ,Hussein E I, Abdel A A, Hamid Al- Smadi M L, et al., 2011.Chemical composition and antimicrobial activity of the volatile oil from white mustard L. and Sinapisarvensis L.(Brassicaceae) growing wild in Jordan. Res. J. Pharm. Biol. Chem. Sci. 2, 1136-1144.

[23] Amensour M, Bouhdid S, Fernandez-Lopez J, Idaomar M, Senhaji S N, and Jamal Abrini J.2010.Antibacterial activity of extracts of Myrtuscommunis against food borne pathogenic and spoilage bacteria. Int.J.Food Proper. 13, 1215-1224.doi:10.1080/10942910903013399.

[24] Anuradha M, Pragyandip D, Murthy P N, Siddique H H., and Kushwaha Poonam A.2012. Classical review on Rajika (Brassicajuncea). Res Rev. J. Bot. Sci. 1, 18-23.

[25] Bailey D, Dalton C, Joseph Daugherty F, \& Tempest a M. 2007. Can a concentrated cranberry extract prevent re current tract infections in women? A pilot study. Phytomedicine, 14(4), 237-241. doi: 10. 10 16/ j. phy med. 2007. 01.004.

[26] Botto B, \& Neuzillet Y.2010. Effectiveness of a cranberry (Vaccinium macrocarpon) preparation in reducing asymptomatic bacteriuria in patients with a perfect enterocystoplasty. Scandinavian Journal of Urology, 44, 165-168.doi: 10. 3109/00365591003636596.

[27] Boyko EJ, Fihn SD, Scholes D, Abraham, Monsey B. 2005. Risk of tract infection and asymptomatic bacteriuria among diabetic and no diabetic postmenopausal woman. Am. J. Epidemiology, 161: 557.

[28] Foxman B. 2002. Epidemiology of tract infections: Incidence, morbidity, and economic costs. American Journal of drugs, 113(1), 5S13S. Doi: 10.1016/S0002- 9343(02)01054-9.

[29] Gupta K, Hooton T M, Naber KG, Wullt B, Colgan R, Miller LG, Super, DE. 2011. International clinical practice guidelines for the treatment of acute uncomplicated cystitis and pyelonephritis in women: A 2010 update by the Infectious Diseases Society of America and therefore the European Society for Microbiology and Infectious Diseases. Clinical Infectious Dis - eases, 52(5), e103-e120. doi: 10. 1093/ cid/ciq257. 
[30] Bansal, VK, Babu V, and Maithil N 2013. Chemistry, anti oxidant and antimicrobial potential of Meg (Myristicafragrans Houtt) J. Genet. Eng. Biotechnol. 11, 25-31. doi:10.1016/j.jgeb.2012.12.001.

[31] Gupta SC, Sung B, Kim JH, Prasad S, Li S, and Aggarwal BB, 2013. Multi targeting by turmeric, the golde spice: from kitchen to clinic. Mol. Nutr. Food Res. 57, 1510 1528.doi:10.1002/mnfr.201100741.

[32] Islam, M.H, Ahmad I. Z, and Salman, MT.2012.Antibacterial activity of Nigellasativa Seed in various germination phases on clinical bacterial strains isolated from human patients. J. Biotechnol. Pharm. Res. 4, 8-13.

[33] Jordán MJ, Lax V, Rota M C, Lorán S, 2013. Effect of bioclimatic area on the volatile oil composition and antibacterial activity of rosemary L. Food Control 30, 463-468. doi: 10.1016/j.foodcont.2012.07.029.

[34] Jepson R, \& Craig J, 2008. Cranberries for preventing tract infections. Cochrane Database of Systematic Reviews, 1. doi: 10. 1002/ 1465 1858. CD 0013 21. pub4.

[35] Jancel, T, \& Dudas V, 2002. Management of uncomplicated tract infections. The Western Journal of drugs, 176(1), 51-55. doi: 10. 1136/ ewjm.176.1.51.

[36] Klein MA, 2005. Cranberry (Vaccinium macrocarpon) Aiton. In: Encyclopedia of Dietary Supplements; Coates, P., Blackman, M.R., Cragg, G., Levine, M., Moss, J., White, J., Eds.; Marcel Dekker: ny, pp. 143- 149.

[37] LiuY, Black MA, Caron L, Camesano T, 2006. Role of fruit juice on molecular-surface characteristics and adhesion behavior of Escherichia coli. Biotechnology and Bio - engineering, 93(2), 297-305.
[38] Liu Y, Zeng T, Chen P, Song Y, Luo Y, and Wang Q.2015.Enhancement of aqueous stability of allyliso thiocyanate using nano emulsions prepared by an emulsion inversion point method. $\mathbf{J}$ Colloid Interface Sci. 438,130-137.doi: 10.1016/j.jcis.2014.09.055.

[39] Mohammad R, Kambiz D, 2010. In vitro activity of cranberry extract against etiological agents of tract infections. Afr. J. Pharm. Pharmacol.4 (5): 286-288.

[40] McMurdo ME, Argo I, Phillips G, Daly F, Davey P, 2009. Cranberry or trimethoprim for the prevention of recurrent tract infections? A randomized controlled trial in older women. J. Antimicrobial. Chemother. 63: 389-395.

[41] O’Bryan CA, Pendleton SJ, Crandall PG., and Ricke SC. 2015. Potential of plant essential oils and their components in animal agriculture- in vitro studies on antibacterial mode of action. Front. Vet. Sci. 2:35. doi: 10.3389/fvets.2015.00035.

[42] Polit DF, \& Beck CT, 2012. Nursing research: Generating and assessing evidence for nursing practice (9thed.) Philadelphia: Lippincott, Williams \& Wilkins.

[43] Puupponen-Pimia“ R, Nohynek L, Meier C, Kahkonen M, Heinonen M, \& Hopia A, et al., 2001. Antimicrobial properties of phenolic compounds from berries. Journal of Applied Microbiology, 90, 494e507.

[44] Rauha JP, Remes S, Heinonen M, Hopia A, Kahkonen M, \& Kujala T, et al, 2000. Antimicrobial effects of Finnish plant extracts containing flavonoids and other phenolic compounds. International Journal of Food Microbiology, 56, 3e12. 